University of Nebraska - Lincoln

DigitalCommons@University of Nebraska - Lincoln

March 1973

\title{
Projected Hartree product wavefunctions. VI. Natural orbital Cl expansions in nonsinglet cases
}

\author{
R.D. Koller \\ University of Nebraska, Lincoln, Nebraska \\ Gordon A. Gallup \\ UNL,ggallup1@unl.edu
}

Follow this and additional works at: https://digitalcommons.unl.edu/physicsgallup

Part of the Physics Commons

Koller, R.D. and Gallup, Gordon A., "Projected Hartree product wavefunctions. VI. Natural orbital Cl expansions in nonsinglet cases" (1973). Gordon Gallup Publications. 36.

https://digitalcommons.unl.edu/physicsgallup/36

This Article is brought to you for free and open access by the Research Papers in Physics and Astronomy at DigitalCommons@University of Nebraska - Lincoln. It has been accepted for inclusion in Gordon Gallup Publications by an authorized administrator of DigitalCommons@University of Nebraska - Lincoln. 


\title{
Projected Hartree product wavefunctions. VI. Natural orbital CI expansions in nonsinglet cases*
}

\author{
R. D. Kollerf and G. A. Gallup \\ Department of Chemistry, University of Nebraska, Lincoln, Nebraska 68508
}

(Received 7 July 1971)

\begin{abstract}
The NSO's and NO's have been determined for some wavefunctions for $\mathrm{Li}, \mathrm{Be}^{1+}, \mathrm{B}^{2+}, \mathrm{C}^{3+}{ }^{2} S$, and $\mathrm{Be}^{3} S$ wavefunctions containing radial correlation. It is shown how the NO's may be utilized to form rapidly converging CI expansions in general. The role of the NSO's in this problem is discussed.
\end{abstract}

\section{INTRODUCTION}

As was shown by Wigner ${ }^{1}$ in his pioneering work on spin and the symmetric groups, a general form for an antisymmetric, eigenfunction of the total spin is

$$
\psi=\sum_{i=1}^{f}\left[{ }_{i=1}^{[\lambda]} \Phi_{i}{ }^{[\hat{\lambda}]} \theta_{i}{ }^{[\lambda]},\right.
$$

where the $\theta_{i}^{[\lambda]}$ are eigenfunctions of $S^{2}$, the $\Phi_{i}{ }^{\hat{\lambda}]}$ are functions of the spatial coordinates, and as the notation indicates the $\Phi_{i}$ and $\theta_{i}$ belong to conjugate irreducible representations of $S_{n}$. As has been emphasized by Gallup, ${ }^{2}$ the calculation of the expectation value of the

Table I. Principal quantum numbers and optimized scale factors for three-electron atoms.

\begin{tabular}{cccccc}
\hline \hline$N$ & $L$ & $\mathrm{Li}$ & $\mathrm{Be}^{+}$ & $\mathrm{B}^{2+}$ & $\mathrm{C}^{3+}$ \\
\hline 1 & 0 & 4.57876 & 6.03010 & 7.59536 & 9.10996 \\
2 & 0 & 4.13290 & 5.48961 & 6.99861 & 8.08749 \\
1 & 0 & 2.71256 & 3.50957 & 4.46902 & 5.40385 \\
2 & 0 & 2.12398 & 2.81384 & 3.58805 & 4.30654 \\
1 & 0 & 0.83048 & 1.01105 & 1.28124 & 1.60147 \\
2 & 0 & 0.62456 & 0.86181 & 1.06087 & 1.32123 \\
2 & 0 & 0.27028 & 0.21496 & 0.25000 & 0.30531 \\
3 & 0 & 0.31405 & 0.11000 & 0.13500 & 0.16350 \\
\hline \hline
\end{tabular}

energy corresponding to the state of Eq. (1) for spinfree Hamiltonian can be obtained from $\Phi_{1}[\hat{\lambda}]$ (or any other) alone, viz.,

$E=\langle\psi|H| \psi\rangle /\langle\psi \mid \psi\rangle=\left\langle\Phi_{1}{ }^{\hat{\lambda}]}|H| \Phi_{1} 1^{\hat{\lambda}]}\right\rangle /\left\langle\Phi_{1}{ }^{[\hat{\lambda}]} \mid \Phi_{1}{ }_{1}^{\hat{\lambda}]}\right\rangle$.

The function $\Phi_{1}{ }^{\hat{\lambda}]}$ can be obtained from a function of arbitrary symmetry with the use of Young operators ${ }^{3}$ based upon the appropriate Young tableau for the spin state desired.

There are a number of ways in which a trial $\Phi_{1}{ }^{[\hat{\lambda}]}=\Phi^{[\hat{\lambda}]}$ may be constructed, for example, by the use of a single Hartree product of arbitrary orbitals or again by using a CI expansion. The single Hartree product form is equivalent to the more conventional DODS procedure ${ }^{4}$ using Slater determinants and spin projection operators. A recent article ${ }^{5}$ discusses calculations of radial correla- tion in the projected Hartree product (PHP) form for some Li-like atoms. It is interesting to examine the natural orbital expansion of these PHP functions, particularly for comparison with other forms of trial functions.

There has not been a large number of calculations of natural orbitals for nonsinglet cases (see however Ref. 6), apparently because there is no obvious way to use natural spin orbitals (NSO) in such cases for the

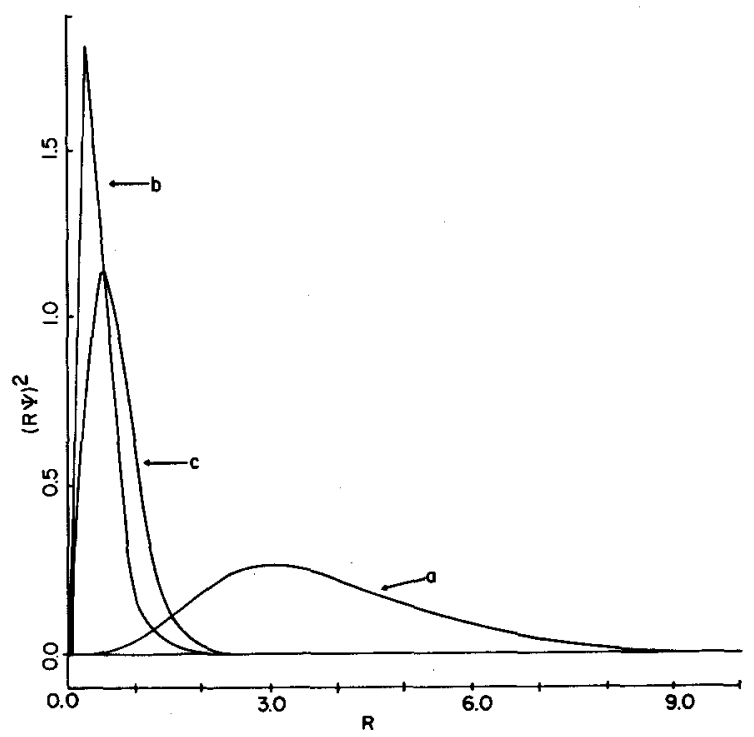

FIG. 1. Radial distribution functions for the PHP orbitals.

conventional CI expansions. In fact, Edmiston ${ }^{7}$ has used NSO's calculated for a singlet case to expand the doublet case for $\mathrm{H}_{3}$. In addition to the calculations of the natural orbitals for ${ }^{2} S \mathrm{Li}$ and ${ }^{3} S \mathrm{Be}$, we examine the problem of expansion of wavefunctions in terms of configurations based on spinless, natural orbitals (NO), and it will be shown that these functions are appropriate for any multiplicity.

\section{FIRST-ORDER DENSITY MATRIX}

The PHP functions for $\mathrm{Li}, \mathrm{Be}^{+}, \mathrm{B}^{2+}$, and $\mathrm{C}^{3+}$ have been given in Ref. 5 and have been further refined with respect to optimization of the exponential scale factors. 
TABLE II. Orbital coefficients, $\gamma$ 's, and energies for three-electron atoms.

\begin{tabular}{|c|c|c|c|c|c|}
\hline \multicolumn{3}{|c|}{$\mathrm{Li}$} & \multicolumn{3}{|c|}{$\mathrm{Be}^{+}$} \\
\hline$a$ & $b$ & $c$ & $a$ & $b$ & $c$ \\
\hline $0.546076 \mathrm{E}-1$ & $0.959160 \mathrm{E} \quad 0$ & $-0.892331 \mathrm{E} \quad 0$ & $-0.216945 \mathrm{E} \quad 0$ & $-0.830806 \mathrm{E} \quad 0$ & $0.691270 \mathrm{E} \quad 0$ \\
\hline $0.448180 \mathrm{E}-1$ & $0.684433 \mathrm{E} \quad 0$ & $-0.798115 \mathrm{E} \quad 0$ & $-0.168359 \mathrm{E} \quad 0$ & $-0.544167 \mathrm{E} \quad 0$ & $0.598058 \mathrm{E} \quad 0$ \\
\hline$-0.129630 \mathrm{E} \quad 0$ & $-0.728074 \mathrm{E} \quad 0$ & $0.263002 \mathrm{E} \quad 1$ & $0.336723 \mathrm{E} \quad 0$ & $0.444020 \mathrm{E} \quad 0$ & $-0.231557 \mathrm{E} \quad 1$ \\
\hline $0.151448 \mathrm{E} \quad 0$ & $0.379203 \mathrm{E} \quad 0$ & $-0.202229 \mathrm{E} \quad 0$ & $-0.673658 \mathrm{E} \quad 0$ & $-0.259998 \mathrm{E} \quad 0$ & $0.219047 \mathrm{E} \quad 0$ \\
\hline$-0.151463 \mathrm{E} \quad 0$ & $-0.194764 \mathrm{E} \quad 0$ & $0.156404 \mathrm{E} \quad 0$ & $0.130767 \mathrm{E}$ & $0.960082 \mathrm{E}-1$ & $-0.930883 E-1$ \\
\hline$-0.104344 \mathrm{E} \quad 1$ & $0.115490 \mathrm{E} \quad 0$ & $-0.947139 \mathrm{E}-1$ & $0.203651 \mathrm{E} \quad 0$ & $-0.337216 \mathrm{E}-1$ & $0.327499 \mathrm{E}-1$ \\
\hline $0.325630 \mathrm{E} \quad 0$ & $-0.156656 \mathrm{E} \quad 0$ & $0.129752 \mathrm{E} \quad 0$ & $-0.143508 \mathrm{E}-1$ & $-0.317583 \mathrm{E}-2$ & $-0.307621 \mathrm{E}-2$ \\
\hline \multirow[t]{3}{*}{$-0.241238 \mathrm{E} \quad 0$} & $0.118396 \mathrm{E} \quad 0$ & $-0.981129 \mathrm{E}-1$ & $0.495478 \mathrm{E}-2$ & $-0.117580 \mathrm{E}-2$ & $0.113826 \mathrm{E}-2$ \\
\hline & \multicolumn{2}{|l|}{$\begin{aligned} E & =-7.44746 \\
\gamma_{1} & =0.433727 \\
\gamma_{2} & =0.427901\end{aligned}$} & \multicolumn{3}{|c|}{$\begin{aligned} E & =-14.2910 \\
\gamma_{1} & =0.437428 \\
\gamma_{2} & =0.428757\end{aligned}$} \\
\hline & \multicolumn{2}{|l|}{$\mathrm{B}^{2+}$} & \multicolumn{3}{|c|}{$\mathrm{C}^{3+}$} \\
\hline$a$ & $b$ & $c$ & $a$ & $b$ & $c$ \\
\hline $0.153546 \mathrm{E} \quad 0$ & $0.729323 \mathrm{E} \quad 0$ & $-0.575990 \mathrm{E} \quad 0$ & $0.104066 \mathrm{E} \quad 0$ & $0.976105 \mathrm{E} \quad 0$ & $-0.811385 \mathrm{E} \quad 0$ \\
\hline $0.114188 \mathrm{E} \quad 0$ & $0.457821 \mathrm{E} \quad 0$ & $-0.479302 \mathrm{E} \quad 0$ & $0.882314 \mathrm{E}-1$ & $0.719240 \mathrm{E} \quad 0$ & $-0.720058 \mathrm{E}$ \\
\hline$-0.156739 \mathrm{E} \quad 0$ & $-0.244581 \mathrm{E} \quad 0$ & $0.209658 \mathrm{E} \quad 1$ & $-0.144313 E-1$ & $-0.780091 \mathrm{E} \quad 0$ & $0.261406 \mathrm{E} \quad 1$ \\
\hline $0.691302 \mathrm{E} \quad 0$ & $0.215019 \mathrm{E} \quad 0$ & $-0.202551 \mathrm{E} \quad 0$ & $0.672323 \mathrm{E} \quad 0$ & $0.331917 \mathrm{E} \quad 0$ & $-0.333514 \mathrm{E} \quad 0$ \\
\hline$-0.160517 \mathrm{E} \quad 1$ & $-0.752324 \mathrm{E}-1$ & $0.765870 \mathrm{E}-1$ & $-0.171653 \mathrm{E} \quad 1$ & $-0.127402 \mathrm{E} \quad 0$ & $0.130135 \mathrm{E} \quad 0$ \\
\hline $0.531100 \mathrm{E}-1$ & $0.265402 \mathrm{E}-1$ & $-0.268409 E-1$ & $0.127449 \mathrm{E} \quad 0$ & $0.416641 \mathrm{E}-1$ & $-0.422992 \mathrm{E}-1$ \\
\hline $0.240497 \mathrm{E}-2$ & $-0.226058 \mathrm{E}-2$ & $0.230751 \mathrm{E}-2$ & $-0.246855 E-2$ & $-0.377695 \mathrm{E}-2$ & $0.380594 \mathrm{E}-2$ \\
\hline \multirow[t]{4}{*}{$-0.100549 \mathrm{E}-2$} & $0.911791 \mathrm{E}-3$ & $-0.931221 \mathrm{E}-3$ & $0.863676 \mathrm{E}-3$ & $0.147580 \mathrm{E}-2$ & $-0.149070 \mathrm{E}-2$ \\
\hline & $E=-23.3895$ & & & $E=-34.7394$ & \\
\hline & $\gamma_{1}=0.440066$ & & & $\gamma_{1}=0.441446$ & \\
\hline & $\gamma_{2}=0.430461$ & & & $\gamma_{2}=0.431635$ & \\
\hline
\end{tabular}

The results are given in Tables I and II. The orbitals for $\mathrm{Be}\left({ }^{3} S\right)$ are given in Table III. The Li orbitals are shown in graphical form in Fig. 1, and the notation of Ref. 5 is followed here. The expression for $\Phi^{[2,1]}$ is

$$
\Phi^{[2,1]}=N P N\left[\gamma_{1} a(1) b(2) c(3)+\gamma_{2} a(1) c(2) b(3)\right]
$$

where $N P N$ is the Young operator for the partition $[2,1] .^{8}$ Knowledge of $\Phi^{[2,1]}$ alone does not constitute knowledge of the complete wavefunction, $\psi$, but group theoretic methods have been given ${ }^{9}$ to deal with operators containing spin, and hence the two spin components of the first-order density matrix for $\psi$ may be deter-

TABLE III. Optimized scale factors, orbital coefficients, $\gamma$ 's, and energy for $\operatorname{Be}\left({ }^{3} S\right)$.

\begin{tabular}{|c|c|c|c|c|c|c|}
\hline \multirow[b]{2}{*}{$N$} & \multirow[b]{2}{*}{$L$} & & \multicolumn{4}{|c|}{ Coeff } \\
\hline & & & $a$ & $b$ & $c$ & $d$ \\
\hline 1 & 0 & 4.50000 & $-0.210647 \mathrm{E} \quad 0$ & $-0.408753 \mathrm{E} \quad 0$ & $0.108143 \mathrm{E} \quad 1$ & $-0.121185 \mathrm{E}$ \\
\hline 2 & 0 & 4.10000 & $-0.763125 E-1$ & $-0.247043 \mathrm{E} \quad 0$ & $0.977677 \mathrm{E}-1$ & $-0.138777 \mathrm{E}$ \\
\hline 1 & 0 & 2.65000 & $0.462648 \mathrm{E} \quad 0$ & $0.698943 \mathrm{E} \quad 0$ & $-0.220156 \mathrm{E} \quad 0$ & $0.142638 \mathrm{E}$ \\
\hline 2 & 0 & 2.10000 & $0.168990 \mathrm{E} \quad 0$ & $-0.472396 \mathrm{E} \quad 0$ & $0.122546 \mathrm{E} \quad 0$ & $-0.344826 \mathrm{E}$ \\
\hline 1 & 0 & 0.75000 & $-0.138298 \mathrm{E}$ & $0.189966 \mathrm{E} \quad 0$ & $-0.572733 \mathrm{E}-1$ & $0.135193 \mathrm{E} \quad 0$ \\
\hline 2 & 0 & 0.60000 & $0.158574 \mathrm{E} \quad 0$ & $-0.732732 \mathrm{E} \quad 0$ & $0.206576 \mathrm{E}-1$ & $-0.476171 \mathrm{E}-1$ \\
\hline 2 & 0 & 0.20000 & $-0.869251 E-1$ & $-0.426214 \mathrm{E} \quad 0$ & $-0.315139 \mathrm{E}-2$ & $0.713187 \mathrm{E}-2$ \\
\hline \multirow[t]{2}{*}{3} & 0 & 0.10000 & $0.210664 \mathrm{E}-1$ & $0.936589 \mathrm{E}-1$ & $0.980246 \mathrm{E}-3$ & $-0.219727 \mathrm{E}-2$ \\
\hline & & & & $\begin{array}{l}E=- \\
\gamma_{1}=1 \\
\gamma_{2}=0 \\
\gamma_{3}=0\end{array}$ & $\begin{array}{l}38547 \\
1124 \\
671 \\
295\end{array}$ & \\
\hline
\end{tabular}


TABLE IV. $\alpha$-NSO's, $\beta$-NSO's, and NO's for Li.

\begin{tabular}{|c|c|c|c|c|}
\hline \multirow[b]{2}{*}{ Orbital } & \multicolumn{3}{|c|}{$\mathrm{Li}$} & \multirow{2}{*}{$\begin{array}{l}\text { Occupation } \\
\text { number }\end{array}$} \\
\hline & $a$ & $b$ & $c$ & \\
\hline \multicolumn{5}{|c|}{ Alpha NSO's } \\
\hline 1 & $0.9988806 \mathrm{E} \quad 0$ & $-0.2489709 \mathrm{E}-2$ & $-0.3332037 \mathrm{E}-2$ & $0.9999994 \mathrm{E} \quad 0$ \\
\hline 2 & $0.1950990 \mathrm{E} \quad 0$ & $0.5198426 \mathrm{E} \quad 0$ & $0.5168829 \mathrm{E} \quad 0$ & $0.9986252 \mathrm{E} \quad 0$ \\
\hline 3 & $0.2590280 \mathrm{E} \quad 0$ & $-0.2686117 \mathrm{E} \quad 1$ & $0.2735792 \mathrm{E} \quad 1$ & $0.1375410 \mathrm{E}-2$ \\
\hline \multicolumn{5}{|c|}{ Beta NSO's } \\
\hline 1 & 0.1050191E 1 & $-0.5793509 \mathrm{E} \quad 0$ & $0.7788625 \mathrm{E} \quad 0$ & $0.6479118 \mathrm{E}-2$ \\
\hline 2 & $-0.2193605 \mathrm{E}-3$ & $0.5034716 \mathrm{E} \quad 0$ & $0.5150992 \mathrm{E} \quad 0$ & $0.9986246 \mathrm{E} \quad 0$ \\
\hline 3 & $-0.4453013 \mathrm{E}-2$ & $-0.2616088 \mathrm{E} \quad 1$ & $0.2622934 \mathrm{E}, 1$ & $0.1374762 \mathrm{E}-2$ \\
\hline \multicolumn{5}{|c|}{ NO's } \\
\hline 1 & $0.1017668 \mathrm{E} \quad 1$ & $0.9869179 \mathrm{E}-1$ & $0.9548502 \mathrm{E}-1$ & $0.1000036 \mathrm{E} \quad 1$ \\
\hline 2 & $0.8271391 \mathrm{E}-3$ & $0.5070069 \mathrm{E} \quad 0$ & $0.5114503 \mathrm{E} \quad 0$ & $0.1997297 \mathrm{E} \quad 1$ \\
\hline 3 & $0.2593690 \mathrm{E} \quad 0$ & $-0.2686759 \mathrm{E} \quad 1$ & $0.2735148 \mathrm{E} \quad 1$ & $0.2667162 \mathrm{E}-2$ \\
\hline
\end{tabular}

mined from $\Phi^{[2,1]}$. The eigenfunctions of this density are the NSO's. Since the wavefunction here depends upon three linearly independent one-particle orbitals, there are three NSO's of $\alpha$-spin and $\beta$-spin type each, and the spatial parts of these functions can be written as linear combinations of $a, b$, and $c$. The NSO's corresponding to the PHP functions for $\mathrm{Li}, \mathrm{Be}^{+}, \mathrm{B}^{2+}, \mathrm{C}^{3+}$, and $\mathrm{Be}\left({ }^{3} S\right)$ are given in Tables IV-VIII, and Figs. 2 and 3 show the spatial parts of these functions for $\mathrm{Li}$ in graphical form. As can be seen the occupation numbers of the NSO's are either quite close to 1 or to zero for these systems.

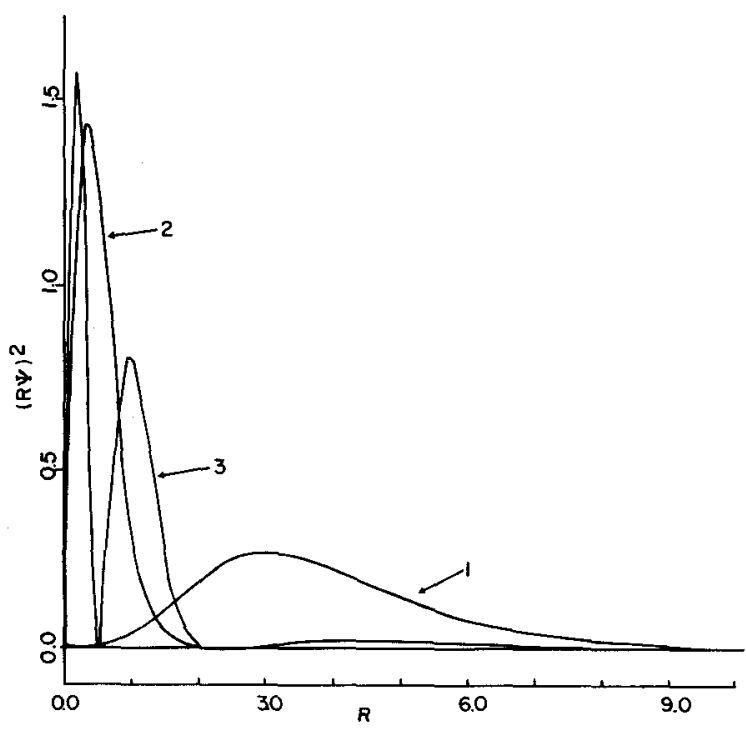

FIG. 2. Radial distribution functions for the $\propto$ NSO's of $\mathrm{Li}$.
If one takes the trace of the spin coordinates only in the first-order density the spinless density matrix is obtained. However, the spinless density matrix, being based on a spin-free operator, may be determined directly from $\Phi^{[2,1]}$ without knowledge of the two components of the density matrix containing spin. This has been done, and the eigenfunctions for the spinless density are the NO's. There are three natural orbitals and these may also be written as linear combinations of $a$, $b$, and $c$. The results for $\mathrm{Li}, \mathrm{Be}^{+}, \mathrm{B}^{2+}, \mathrm{C}^{3+}$, and $\mathrm{Be}\left({ }^{3} S\right)$ are also given in Tables IV-VIII and a graphical representation of the NO's for $\mathrm{Li}$ is shown in Fig. 4. It is seen that the occupation numbers here are close to 2 , 1 , or 0 .

\section{THE CI EXPANSION OF THE PHP WAVEFUNCTION IN TERMS OF NATURAL ORBITALS}

As was stated earlier a $\mathrm{CI}$ expansion representation for $\Phi^{[\hat{\lambda}]}$ is possible. To discuss this we assume that we have a complete orthonormal set of one-particle spatial functions $u_{1}, u_{2}, u_{3}, \cdots$. As is well known, a tensor space, $V$, for $n$ particles may be constructed by taking all possible products of the form,

$$
R(\bar{i})=u_{i_{1}}(1) \cdots u_{i_{n}}(n),
$$

as a basis, and these product functions constitute a complete, orthonormal basis for this $n$-particle tensor space. The function we wish to represent has, however, a certain symmetry specification. ${ }^{8}$ viz.,

$$
\theta N P N \Phi^{[\lambda]}=\Phi^{[\hat{\lambda}]} \text {. }
$$

Now, the functions $N P N R(\bar{\imath})$ completely span the sub- 
TABLE V. $\alpha$ NSO's, $\beta$ NSO's, and NO's for Be ${ }^{+}$.

\begin{tabular}{|c|c|c|c|c|c|}
\hline \multirow[b]{2}{*}{ Orbital } & \multicolumn{4}{|c|}{$\mathrm{Be}^{+}$} & \multirow{2}{*}{$\begin{array}{c}\text { Occupation } \\
\text { number }\end{array}$} \\
\hline & $a$ & $b$ & $c$ & & \\
\hline \multicolumn{6}{|c|}{ Alpha NSO's } \\
\hline 1 & $0.9964345 \mathrm{E} \quad 0$ & $0.5905868 \mathrm{E}-2$ & $0.7582089 \mathrm{E}-$ & & $0.9999991 \mathrm{E} \quad 0$ \\
\hline 2 & $-0.2765789 \mathrm{E} \quad 0$ & $\begin{array}{lll}0.5260218 \mathrm{E} & 0\end{array}$ & $0.5215507 \mathrm{E}$ & 0 & $0.9993397 \mathrm{E} \quad 0$ \\
\hline 3 & $-0.3569385 \mathrm{E} \quad 0$ & $-0.3263250 \mathrm{E} \quad 1$ & $0.3356134 \mathrm{E}$ & 1 & $0.6611367 \mathrm{E}-3$ \\
\hline \multicolumn{6}{|c|}{ Beta NSO's } \\
\hline 1 & $0.1093920 \mathrm{E} \quad 0$ & $0.9683403 \mathrm{E} \quad 0$ & $-0.1251501 \mathrm{E}$ & 1 & $0.8645581 E-6$ \\
\hline 2 & $0.3644778 \mathrm{E}-3$ & $0.4976630 \mathrm{E} \quad 0$ & $0.5152553 \mathrm{E}$ & 0 & $0.9993389 \mathrm{E} \quad 0$ \\
\hline 3 & $0.1098732 \mathrm{E}-1$ & $-0.3120927 \mathrm{E} \quad 1$ & $0.3115119 \mathrm{E}$ & 1 & $0.6602722 \mathrm{E}-3$ \\
\hline \multicolumn{2}{|c|}{ ' } & NO's & & & \\
\hline 1 & $0.1034031 \mathrm{E} \quad 1$ & $-0.1365115 \mathrm{E} \quad 0$ & $-0.1323157 \mathrm{E}$ & 0 & $0.1000027 \mathrm{E} \quad 1$ \\
\hline 2 & $0.1119215 \mathrm{E}-2$ & $0.5029285 \mathrm{E} \quad 0$ & $0.5097975 \mathrm{E}$ & 0 & $0.1998721 \mathrm{E} \quad 1$ \\
\hline 3 & $-0.3571561 \mathrm{E} \quad 0$ & $-0.3264041 \mathrm{E} \quad 1$ & $0.3355340 \mathrm{E}$ & 1 & $0.1252272 \mathrm{E}-2$ \\
\hline
\end{tabular}

space of $V$ appropriate for functions of symmetry type according to Eq. (4). They are not all linearly independent, however. The theory of representations of the symmetric group $S_{n}$ tells how to choose a linearly independent set from all $N P N R(\bar{\imath})$. We consider two Young tableaux, corresponding to the partition $[\hat{\lambda}]=$ $\left[2^{n / 2-S}, 1^{2 S}\right]$, where $S$ is the total spin quantum number of the wavefunction of Eq. (1). The first we call the particle tableau, particle subscripts 1 to $n / 2+S$ in the first column and $n / 2+S+1$ to $n$ in the second column. This determines the permutations and their numbers in the Young operator NPN. The second tableau contains as entries the subscripts of the symbols for the original

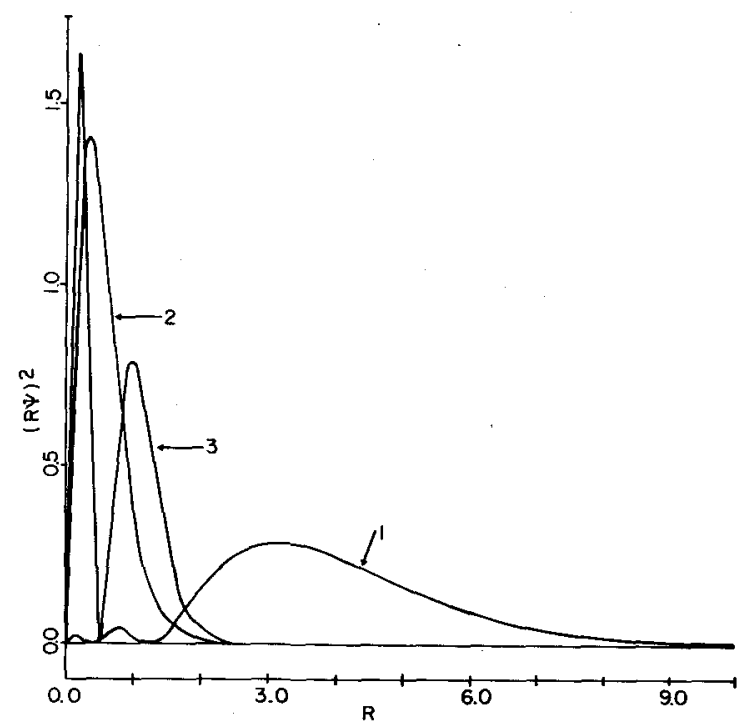

FIG. 3. Radial distribution functions for the $\beta$ NSO's of $\mathbf{L i}$. orthonormal set, $u_{1}, u_{2}, u_{3} \cdots$, ordered to give standard tableaux. These are called function tableaux, and matching the particle tableau with the function tableau gives us a particular product function,

$$
R(\bar{k})=u_{k_{1}}(1) \cdots u_{k_{n}}(n) .
$$

The set of functions $N P N R(\bar{k})$ for all possible $\bar{k}$ satisfying the standard tableau requirements, forms a complete set for expansions of functions of symmetry given by Eq. (4). The functions $R(k)$ can be considered to be based upon a set of ordered configurations, $\bar{\alpha}(k)$,

$$
u_{1}^{\alpha_{1}(k)} u_{2}^{\alpha_{2}(k)} u_{3}^{\alpha_{3}(k)} \ldots \text {, }
$$

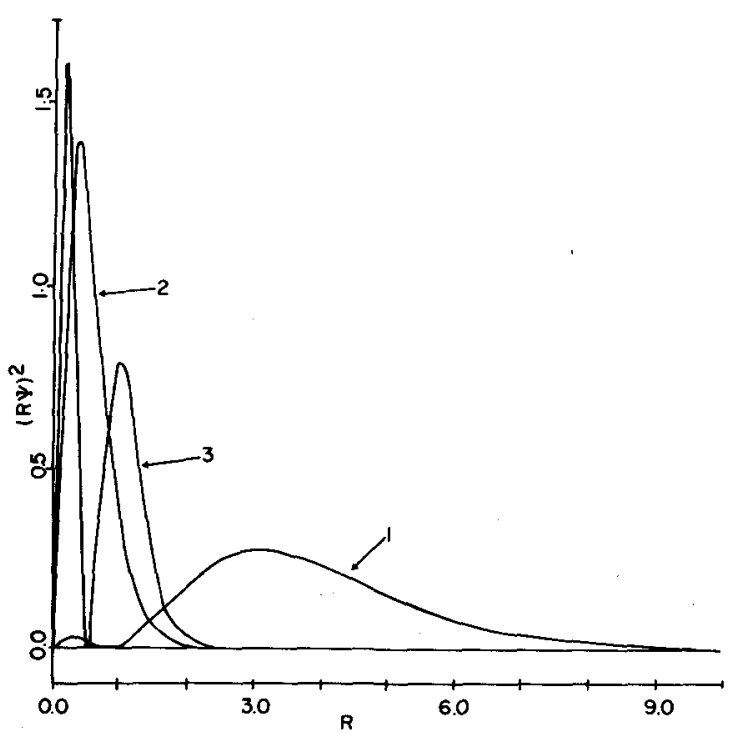

FIG. 4. Radial distribution functions for the NO's of $\mathrm{Li}$. 
TABLE VI. $\alpha$ NSO's, $\beta$ NSO's, and NO's for $\mathrm{B}^{2+}$.

\begin{tabular}{|c|c|c|c|c|}
\hline \multirow[b]{2}{*}{ Orbital } & \multicolumn{3}{|c|}{$\mathrm{B}^{2+}$} & \multirow{2}{*}{$\begin{array}{c}\text { Occupation } \\
\text { number }\end{array}$} \\
\hline & $a$ & $b$ & $c$ & \\
\hline \multicolumn{5}{|c|}{ Alpha NSO's } \\
\hline 1 & $0.9943024 \mathrm{E} \quad 0$ & $-0.8354249 \mathrm{E}-2$ & $-0.1044516 \mathrm{E}-1$ & $0.9999993 \mathrm{E} \quad 0$ \\
\hline 2 & $0.3229171 \mathrm{E} \quad 0$ & $0.5304064 \mathrm{E} \quad 0$ & $0.5253863 \mathrm{E} \quad 0$ & $0.9996151 \mathrm{E} \quad 0$ \\
\hline 3 & $0.4086156 \mathrm{E} \quad 0$ & $-0.3768765 \mathrm{E} \quad 1$ & $0.3889872 \mathrm{E} \quad 1$ & $0.3856344 \mathrm{E}-3$ \\
\hline \multicolumn{5}{|c|}{ Beta NSO's } \\
\hline 1 & $0.1122330 \mathrm{E} \quad 1$ & $-0.1277239 \mathrm{E} \quad 1$ & $0.1608647 \mathrm{E}$ & $0.7380095 \mathrm{E}-6$ \\
\hline 2 & $-0.3963070 \mathrm{E}-3$ & $0.4950837 \mathrm{E} \quad 0$ & $0.5147655 \mathrm{E}$ & $0.9996144 \mathrm{E} \quad 0$ \\
\hline 3 & $-0.1596071 \mathrm{E}-1$ & $-0.3550852 \mathrm{E} \quad 1$ & $0.3543212 \mathrm{E}$ & $0.3848964 \mathrm{E}-3$ \\
\hline \multicolumn{5}{|c|}{ NO's } \\
\hline 1 & $0.1045368 \mathrm{E} \quad 1$ & $0.1572598 \mathrm{E} \quad 0$ & $0.1526875 \mathrm{E}$ & $0.1000018 \mathrm{E} \quad 1$ \\
\hline 2 & $-0.1149716 \mathrm{E}-2$ & $0.5009248 \mathrm{E} \quad 0$ & $0.5087047 \mathrm{E}$ & $0.1999262 \mathrm{E} \quad 1$ \\
\hline 3 & $0.4087579 \mathrm{E} \quad 0$ & $-0.3769527 \mathrm{E} \quad 1$ & $0.3889106 \mathrm{E}$ & $0.7206672 E-3$ \\
\hline
\end{tabular}

where each of the occupation numbers, $\alpha_{i}(k)$, is either 2,1 , or 0 and $\sum_{i} \alpha_{i}(k)=n$. The $\alpha_{i}(k)$ must satisfy a certain constraint, which may be written as

$$
n_{s}[\bar{\alpha}(k)] \equiv \sum_{i}\left(2-\alpha_{i}\right) \alpha_{i} \geq 2 S .
$$

It is seen that this is just the number of singly occupied orbitals.

In general, there is more than one standard tableau for each set of occupation numbers $\bar{\alpha}$ and the number of these is

$$
f(k)=\frac{2 S+1}{n_{s}(\bar{\alpha})+1}\left(\begin{array}{c}
n_{s}(\bar{\alpha})+1 \\
n_{s}(\bar{\alpha}) / 2-S
\end{array}\right) .
$$

\section{NATURAL ORBITAL EXPANSION OF $\Phi^{\hat{\lambda}]}$}

For an arbitrary function of the spatial coordinates of $n$ particles there are $n$, in general different, first-order densities. This is because the coordinates left uninte-

\begin{tabular}{|c|c|c|c|c|c|c|}
\hline \multirow[b]{2}{*}{ Orbital } & \multicolumn{5}{|c|}{$\mathrm{C}^{3+}$} & \multirow{2}{*}{$\begin{array}{l}\text { Occupation } \\
\text { number }\end{array}$} \\
\hline & $a$ & $b$ & & $c$ & & \\
\hline \multicolumn{7}{|c|}{ Alpha NSO's } \\
\hline 1 & $0.9928930 \mathrm{E} \quad 0$ & $-0.9877769 \mathrm{E}-2$ & & $-0.1212952 \mathrm{E}-$ & & $0.9999994 \mathrm{E} \quad 0$ \\
\hline 2 & $0.3475875 \mathrm{E} \quad 0$ & $0.5328617 \mathrm{E}$ & 0 & $0.5276989 \mathrm{E}$ & 0 & $0.9997362 \mathrm{E} \quad 0$ \\
\hline 3 & $0.4360760 \mathrm{E} \quad 0$ & $-0.4165971 \mathrm{E}$ & 1 & $0.4303198 \mathrm{E}$ & 1 & $0.2645057 \mathrm{E}-3$ \\
\hline \multicolumn{7}{|c|}{ Beta NSO's } \\
\hline 1 & $0.1138618 \mathrm{E} \quad 1$ & $-0.1506449 \mathrm{E}$ & 1 & $0.1863772 \mathrm{E}$ & 1 & $0.6044257 \mathrm{E}-6$ \\
\hline 2 & $-0.3888364 E-3$ & $0.4940157 \mathrm{E}$ & $\mathbf{0}$ & $0.5141256 \mathrm{E}$ & 0 & $0.9997355 \mathrm{E} \quad 0$ \\
\hline 3 & $-0.1907614 \mathrm{E}-1$ & $-0.3889205 \mathrm{E}$ & 1 & $0.3880484 \mathrm{E}$ & 0 & $0.2639013 \mathrm{E}-3$ \\
\hline \multicolumn{7}{|c|}{ NO's } \\
\hline 1 & $0.1051933 \mathrm{E} \quad 1$ & $0.1679709 \mathrm{E}$ & 0 & $0.1633199 \mathrm{E}$ & 0 & $0.1000013 \mathrm{E} \quad 1$ \\
\hline 2 & $-0.1099319 \mathrm{E}-2$ & $0.4999635 \mathrm{E}$ & $\mathbf{0}$ & $0.5079574 \mathrm{E}$ & 0 & $0.1999497 \mathrm{E} \quad 1$ \\
\hline 3 & $0.4361791 \mathrm{E} \quad 0$ & $-0.4166675 \mathrm{E}$ & 1 & $0.4302492 \mathrm{E}$ & 1 & $0.4907071 \mathrm{E}-3$ \\
\hline
\end{tabular}

TABLE VII. $\alpha$ NSO's, $\beta$ NSO's, and NO's for $\mathrm{C}^{3+}$. 
TABLE VIII. $\alpha$ NSO's, $\beta$ NSO's, and NO's for $\mathrm{Be}\left({ }^{3} S\right)$.

\begin{tabular}{|c|c|c|c|c|c|}
\hline \multirow[b]{2}{*}{ Orbital } & \multicolumn{4}{|c|}{$\mathrm{Be}$} & \multirow{2}{*}{$\begin{array}{l}\text { Occupation } \\
\text { number }\end{array}$} \\
\hline & $a$ & $b$ & $c$ & $d$ & \\
\hline \multicolumn{6}{|c|}{ Alpha NSO's } \\
\hline 1 & $0.1356444 \mathrm{E}$ & $-0.4789954 \mathrm{E} \quad 0$ & $0.4098474 \mathrm{E} \quad 0$ & $0.5495299 \mathrm{E}-1$ & $0.9961466 \mathrm{E} \quad 0$ \\
\hline 2 & $-0.8917479 \mathrm{E} \quad 0$ & $0.1528405 \mathrm{E}$ & $0.2693233 \mathrm{E}-1$ & $-0.4246156 \mathrm{E}-1$ & $0.9963415 \mathrm{E} \quad 0$ \\
\hline 3 & $-0.2130067 \mathrm{E} \quad 0$ & $0.8345794 \mathrm{E}-1$ & $0.6638490 \mathrm{E} \quad 0$ & $0.2879802 \mathrm{E} \quad 0$ & $0.9996820 \mathrm{E} \quad 0$ \\
\hline 4 & $0.6289829 \mathrm{E} \quad 0$ & $-0.2530711 \mathrm{E} \quad 0$ & $-0.3219215 \mathrm{E} \quad 1$ & $0.3433627 \mathrm{E} \quad 1$ & $0.7829871 \mathrm{E}-2$ \\
\hline \multicolumn{6}{|c|}{ Beta NSO's } \\
\hline 1 & $0.1323974 \mathrm{E} \quad 1$ & $-0.4669206 \mathrm{E} \quad 0$ & $0.5763166 \mathrm{E} \quad 0$ & $-0.1844787 \mathrm{E} \quad 0$ & $0.3853414 \mathrm{E}-2$ \\
\hline 2 & $-0.8932916 \mathrm{E} \quad 0$ & $0.1529057 \mathrm{E} \quad 1$ & $0.3886747 \mathrm{E}-1$ & $-0.7782480 \mathrm{E}-2$ & $0.3658463 \mathrm{E}-2$ \\
\hline 3 & $-0.3826011 \mathrm{E}-1$ & $0.1537390 \mathrm{E}-1$ & $0.2821101 \mathrm{E} \quad 0$ & $0.7183527 \mathrm{E} \quad 0$ & $0.9921701 \mathrm{E} \quad 0$ \\
\hline 4 & $0.7237432 E \quad 0$ & $-0.2831998 \mathrm{E} \quad 0$ & $-0.3249539 \mathrm{E} \quad 1$ & $0.3365357 \mathrm{E} \quad 1$ & $0.3179938 \mathrm{E}-3$ \\
\hline \multicolumn{6}{|c|}{ NO's } \\
\hline 1 & $-0.1057337 \mathrm{E} \quad 0$ & $0.1094307 \mathrm{E} \quad 1$ & $0.2035192 \mathrm{E} \quad 0$ & $0.1937192 \mathrm{E} \quad 0$ & $\begin{array}{ll}0.9999993 \mathrm{E} & 0\end{array}$ \\
\hline 2 & $-0.1629428 \mathrm{E} \quad 1$ & $0.1171587 \mathrm{E} \quad 1$ & $-0.3034437 \mathrm{E}$ & $-0.2867145 \mathrm{E}-1$ & $0.1000002 \mathrm{E} \quad 1$ \\
\hline 3 & $-0.7854427 \mathrm{E}-1$ & $0.3157543 \mathrm{E}-1$ & $0.4870729 \mathrm{E}$ & $0.5056933 \mathrm{E} \quad 0$ & $0.1984043 \mathrm{E} \quad 1$ \\
\hline 4 & $\begin{array}{lll}0.6354225 \mathrm{E} & 0\end{array}$ & $-0.2556335 \mathrm{E} \quad 0$ & $-0.3256071 \mathrm{E} \quad 1$ & $0.3408640 \mathrm{E} \quad 1$ & $0.1595575 \mathrm{E}-1$ \\
\hline
\end{tabular}

grated in the formula

$$
\gamma_{i}\left(r_{i} \mid r_{i}{ }^{\prime}\right) \equiv \int f\left(r_{1} \cdots r_{i}{ }^{\prime} \cdots r_{n}\right) * f\left(r_{1} \cdots r_{i} \cdots r_{n}\right) d \tau_{i}
$$

could be chosen to refer to any of the particles. The symbol $d \tau_{i}$ is to indicate that integration over the $i$ th coordinate set is omitted. The various $\gamma_{i}$ could even be orthogonal and hence the corresponding eigenfunctions are also orthogonal, and these densities could describe and treat different particles in quite different ways. This situation would be far from satisfactory physically if one is dealing with identical particles. A way around the difficulty is to use as a density the symmetric sum of all of the $\gamma_{i}$,

$$
\gamma\left(\rho \mid \rho^{\prime}\right)=\sum_{i} \gamma_{i}\left(\rho \mid \rho^{\prime}\right),
$$

so that $\gamma$ represents all particles on equal footing. This prescription has the additional advantage in that it gives the conventional Löwdin-normalized, spinless density corresponding to $\psi$ in Eq. (1) if Eqs. (7) and (8) are applied to $\Phi^{(\hat{\lambda})}$. It should be pointed out that although the $\gamma\left(\rho \mid \rho^{\prime}\right)$ calculated this way is independent of $i$ in $\Phi_{i}{ }^{(\lambda)}$, the $n$ different densities defined in Eq. (7) can differ from one another in quite different ways for different $i$ in $\Phi_{i}{ }^{(\hat{\lambda}]}$.

It has been shown (10) that if a wavefunction is to be represented by a CI expansion in terms of a finite set of orbitals, $m$ in number, the best approximation in the least squares sense to the correct function is obtained if the $m$ NSO's of largest occupation number are used. A rather similar theorem can be proved for the NO's which are the eigenfunctions of $\gamma\left(\rho \mid \rho^{\prime}\right)$. We will outline the proof since there are some details different from the proof for NSO's.
As was shown in Sec. III a complete set of $n$ particle functions $N P N R(\bar{i})$ can be constructed appropriate to the symmetry of $\Phi_{1}{ }^{[\hat{\lambda}]}$. We must make our notation more definite. This complete set of functions may be catalogued in terms of an ordered set of configurations $[\bar{\alpha}(k)]=\left[\alpha_{1}(k) \cdots\right]$. We need two indices on the functions, however, the second represents the different standard tableaux possible for the given set of occupation number $[\bar{\alpha}(k)]$, hence we write

$$
\phi_{i}(k)=a_{k} N P N R_{i}(k) ; \quad k=1,2, \cdots ; \quad i=1,2, \cdots, f(k),
$$

where $f(k)$ is given by Eq. (6), and $a_{k}$ is a normalization constant. Examination of the form of $N P N^{8}$ shows that the $\phi_{i}(k)$ are not all orthogonal, but one has

$$
\left\langle\phi_{i}(k) \mid \phi_{i^{\prime}}\left(k^{\prime}\right)\right\rangle=\delta_{k k^{\prime}} S_{i i^{\prime}}(k) .
$$

Functions corresponding to different configurations are orthogonal, but there is an overlap matrix between functions corresponding to different standard tableaux for the same configuration. All of the $S(k)$ matrices are nonsingular since the set $\phi_{i}(k)$ is linearly independent. $\Phi^{\hat{[} \hat{\lambda}]}$ may be expanded in terms of $\phi_{i}(k)$,

$$
\Phi^{\hat{\lambda} \mathbf{\lambda}}=\sum_{k, i} C_{k i} \phi_{i}(k)
$$

where

$$
C_{k i}=\sum_{j}\left[S(k)^{-1}\right]_{j i}\left\langle\phi_{j}(k) \mid \Phi^{[\hat{\wedge}]}\right\rangle
$$

and

$$
1=\left\langle\Phi^{[\hat{\lambda}]} \mid \Phi^{[\hat{\Lambda}]}\right\rangle=\sum_{k i j} C_{k i}^{*} C_{k j} S_{i j}(k) .
$$

If the $\phi_{i}(k)$ are constructed from an arbitrary, complete 
TABLE IX. NO CI expansion coefficients and their squares for three-electron atoms.

\begin{tabular}{|c|c|c|c|c|}
\hline Coeff & $\mathbf{L i}$ & $\mathrm{Be}^{+}$ & $\mathrm{B}^{2+}$ & $\mathrm{C}^{3+}$ \\
\hline$C_{11}$ & $0.999314 \mathrm{E} \quad 0$ & $0.999671 \mathrm{E} \quad 0$ & $0.999810 \mathrm{E} \quad 0$ & $0.999879 \mathrm{E} \quad 0$ \\
\hline$C_{21}$ & $-0.353565 \mathrm{E}-1$ & $-0.233966 \mathrm{E}-1$ & $-0.173732 \mathrm{E}-1$ & $-0.141598 \mathrm{E}-1$ \\
\hline$C_{3 \mathrm{I}}$ & $0.898410 \mathrm{E}-2$ & $0.807842 \mathrm{E}-2$ & $0.679051 \mathrm{E}-2$ & $0.586900 \mathrm{E}-1$ \\
\hline$C_{41}$ & $0.671130 \mathrm{E}-2$ & $0.621017 \mathrm{E}-2$ & $0.533303 \mathrm{E}-2$ & $0.465381 \mathrm{E}-2$ \\
\hline$C_{51}$ & $-0.341765 \mathrm{E}-3$ & $-0.217705 \mathrm{E}-3$ & $-0.141876 \mathrm{E}-3$ & $1.102429 \mathrm{E}-3$ \\
\hline$C_{61}$ & $0.270646 \mathrm{E}-3$ & $0.182688 \mathrm{E}-3$ & $0.123145 \mathrm{E}-3$ & $0.903128 \mathrm{E}-4$ \\
\hline$C_{71}$ & $0.173552 \mathrm{E}-2$ & $0.212516 \mathrm{E}-2$ & $0.203814 \mathrm{E}-2$ & $0.187896 \mathrm{E}-2$ \\
\hline$C_{72}$ & $-0.336243 \mathrm{E}-3$ & $-0.372896 \mathrm{E}-3$ & $-0.334585 \mathrm{E}-3$ & $-0.302563 \mathrm{E}-3$ \\
\hline$P_{1}$ & 0.998628 & 0.999342 & 0.999619 & 0.999740 \\
\hline$P_{2}$ & 0.001243 & 0.000547 & 0.000302 & 0.000201 \\
\hline$P_{3}$ & 0.000081 & 0.000065 & 0.000046 & 0.000034 \\
\hline$P_{4}$ & 0.000045 & 0.000039 & 0.000028 & 0.000022 \\
\hline$P_{5}$ & 0.000000 & 0.000000 & 0.000000 & 0.000000 \\
\hline$P_{6}$ & 0.000000 & 0.000000 & 0.000000 & 0.000000 \\
\hline$P_{7}$ & 0.000003 & 0.000004 & 0.000004 & 0.000003 \\
\hline
\end{tabular}

orthonormal basis, we have

$$
\gamma\left(\rho \mid \rho^{\prime}\right)=\sum_{p m} \gamma_{p m} u_{p}(\rho) u_{m}\left(\rho^{\prime}\right)^{*} .
$$

From the form of $N P N$ it is seen

$$
\begin{gathered}
\gamma_{p p}=\sum_{k} \alpha_{p}(k) \sum_{i j} C_{k i}{ }^{*} C_{k j} S_{i j}(k), \\
\sum_{p} \gamma_{p p}=\operatorname{Tr}(\gamma)=n, \\
\gamma_{p m}=\sum_{k k^{\prime}}\left[\alpha_{k}(k), \alpha_{m}\left(k^{\prime}\right)\right] \sum_{i j} C_{k i}{ }^{*} C_{k^{\prime} j} S_{i j}\left(k, k^{\prime}\right),
\end{gathered}
$$

where $\left[\alpha, \alpha^{\prime}\right]$ is a symbol standing for +1 if $\left|\alpha-\alpha^{\prime}\right|=1$ and is zero otherwise. $S_{i j}\left(k, k^{\prime}\right)$ is the coefficient in $N P N$ of one particular permutation. This is the permutation that transforms the $j$ th tableau of $\bar{\alpha}\left(k^{\prime}\right)$ into the $i$ th tableau of $\bar{\alpha}(k)$ except for the one position differing between $\bar{\alpha}(k)$ and $\bar{\alpha}\left(k^{\prime}\right)$.

From Eq. (15) it is easily seen that $2 \geq \gamma_{p p} \geq 0$ and is equal to 2 only if $u_{p}$ is doubly occupied in all configurations and equal to 0 only if $u_{p}$ is missing from all configurations. $\gamma_{p p}$ will equal 1 if $\alpha_{p}(k)=1$ in all configurations but this is not necessary, merely sufficient. We shall come back to this point later.

As is well known, if we choose $m$ functions from the set $u_{1} u_{2} \cdots$ and form all the configurations possible with this truncated set, the best least squares approximation to $\Phi_{1}{ }^{\hat{\lambda}]}$ is obtained when $\Delta$, given by

$$
\Delta=\int\left|\Phi_{1}{ }^{\hat{\lambda}]}-\sum_{k i} C_{k i} \phi_{i}(k)\right|^{2} d \tau
$$

is a minimum, and the minimum is attained when the $C_{k i}$ are given by Eq. (12). The sum in Eq. (17) is over only those configurations arising from the set of $m$ orbitals. An easy calculation shows that

$$
\Delta=1-\left(n_{i}\right)^{-1} \sum \gamma_{i i},
$$

where the sum is over $\gamma_{i i}$ for the set of $m$ functions chosen. The quantity $\Delta$ will be a minimum when $\sum_{i} \gamma_{i i}$ is a maximum, and this will be the situation when the matrix $\gamma$ is diagonal and we choose orbitals corresponding to the $m$ largest eigenvalues. This proof follows exactly the form given by Löwdin for NSO's. ${ }^{10}$ Therefore, the NO's, eigenfunctions of $\gamma\left(\rho \mid \rho^{\prime}\right)$ yield the most rapidly converging CI expansion of $\Phi_{1}[\hat{\lambda}]$.

The inequality expressed by Eq. (5) holds in general. Let us define $P_{k}$,

$$
P_{k}=\sum_{i j} C_{k i} * C_{k j} S_{i j}(k), \quad 0 \leq P_{k} \leq 1, \quad \sum_{k} P_{k}=1,
$$

and we have

$$
\gamma_{p p}=\sum_{k} P_{k} \alpha_{p}(k)
$$

If $\gamma$ is diagonal we have

$$
\operatorname{Tr}\left(2 \gamma-\gamma^{2}\right)=2 n-\sum_{k k^{\prime}} P_{k} P_{k^{\prime}} \sum_{p} \alpha_{p}(k) \alpha_{p}\left(k^{\prime}\right) .
$$

Using Eq. (5) and the fact that

$$
\alpha_{p}(k) \alpha_{p}\left(k^{\prime}\right) \leq \frac{1}{2}\left[\alpha_{p}(k)^{2}+\alpha_{p}\left(k^{\prime}\right)^{2}\right],
$$

Eq. (22) becomes the inequality

$$
\operatorname{Tr}\left(2 \gamma-\gamma^{2}\right) \geq 2 S \text {. }
$$

When one is considering arbitrary antisymmetric functions it may be shown that if the density matrix containing spin is idempotent, the original function is a single Slater determinant. It is interesting to examine the corresponding situation for these NO expansions. If the density satisfies the reduced characteristic equation,

$$
\gamma(1-\gamma)(2-\gamma)=0,
$$

then all its eigenvalues are either 0,1 , or 2 exactly, and under these circumstances,

$$
\operatorname{Tr}\left(2 \gamma-\gamma^{2}\right)=n_{s},
$$

the number of exactly singly occupied NO's. The num- 
TABLE X. NO CI expansion coefficients and their squares for $\mathrm{Be}\left({ }^{3} S\right)$.

\begin{tabular}{|c|c|}
\hline Coeff. & $\mathrm{Be}$ \\
\hline$C_{11}$ & 0.992202 \\
\hline$C_{21}$ & -0.021869 \\
\hline$C_{3}$ & -0.002746 \\
\hline$C_{4}$ & -0.002324 \\
\hline$C_{5} 1$ & -0.001560 \\
\hline$C_{6} 1$ & 0.000135 \\
\hline$C_{7}$ & -0.000819 \\
\hline$C_{8} 1$ & 0.000377 \\
\hline$C_{9}{ }_{1}$ & -0.000355 \\
\hline$C_{101}$ & 0.000348 \\
\hline$C_{111}$ & 0.000161 \\
\hline$C_{121}$ & 0.000100 \\
\hline$C_{131}$ & -0.000145 \\
\hline$C_{132}$ & -0.106132 \\
\hline$C_{133}$ & 0.106132 \\
\hline$P_{1}$ & 0.984464 \\
\hline$P_{2}$ & 0.000478 \\
\hline$P_{3}$ & 0.000008 \\
\hline$P_{4}$ & 0.000005 \\
\hline$P_{5}$ & 0.000002 \\
\hline$p_{6}$ & 0.000002 \\
\hline$P_{7}$ & 0.000001 \\
\hline$P_{8}$ & 0.000000 \\
\hline$P_{9}$ & 0.000000 \\
\hline$P_{10}$ & 0.000000 \\
\hline$P_{11}$ & 0.000000 \\
\hline$P_{12}$ & 0.000000 \\
\hline$P_{13}$ & 0.015039 \\
\hline
\end{tabular}

ber of doubly occupied NO's is evidently $\left(n-n_{s}\right) / 2$. Using Eqs. (22) and (23) we get

$$
0 \leq \sum_{k} P_{k}\left[n_{s}-n_{s}(k)\right] \text {, }
$$

where $n_{s}(k)$ is the number of singly occupied orbitals in the $k$ th configuration. Since the $P_{k}$ are nonnegative but otherwise sufficiently arbitrary, and using Eq. (5) we see that

$$
2 S \leq n_{s}(k) \leq n_{s}
$$

for all configurations contained in the function. Since only a finite number of the $\gamma_{p p}$ are nonzero we have only a finite number of configurations (when expressed in terms of the NO's) and if we denote this number by $N_{c}$ we have

$$
N_{c}=\sum_{p=0}^{p_{\max }}\left(\begin{array}{c}
n_{s} \\
p
\end{array}\right)\left(\begin{array}{c}
n_{s}-p \\
p
\end{array}\right),
$$

where $p_{\max }=\left(n_{s} / 2\right)-s$. It is easily seen that if we let $P_{k}=1 / N_{c}$ for these configurations present, $\gamma$ will have the form assumed. This is, of course, only one of an infinity of sets of $P_{k}$ 's which give this form for $\gamma$. The only exception is when $n_{s}=2 S$, and then there is one and only one configuration present in $\Phi_{1}{ }^{[\hat{\lambda}]}$ and there is only one standard tableau for this configuration. We conclude, therefore, any or all of the configurations satisfying Eq. (28) may appear. There are some restrictions on the values of the $P_{k}$ 's but these will not be discussed here.

It is seen that there is no simple way to use the NSO's to represent the function $\Phi_{1}{ }_{1}^{\hat{\lambda}]}$ and hence $\psi$ unless $S=0$, where the NO's and NSO's are very closely related. Indeed, the form for $\psi$ given in Eq. (1) clearly dissociates the spin state of each particle from any spatial properties of that particle except for the case of a single particle, where $\psi$ given in Eq. (1) is just a single spin orbital. If, on the other hand, it is wished to represent $\psi$ by a sum of Slater determinants constructed from spin orbitals, the use of a spin projection operator is in general required to obtain a pure spin state. This procedure again mixes up the spatial and spin characters of the individual particles and one is back to Eq. (1). The only exception is the single doubly occupied Slater determinant, but this is already in the form of Eq. (1), or alternatively it may be said that the double occupancy means that differing spin properties of a particle are not distinguished by differing spatial properties. Of course, the preceding comments apply only if $H$ is spin free to a good approximation and $S$ is a good quantum number, with no fields present which destroy the isotropic nature of spin space.

\section{NATURAL EXPANSIONS}

Since the NO's and the PHP orbitals are both linearly independent, the transformation between them is nonsingular and may be inverted. Therefore, the orbitals $a, b$, and $c$ may be written as linear combinations of the natural orbitals $u_{1}, u_{2}$, and $u_{3}$. If these are substituted into Eq. (3) and the various terms multiplied out and collected, we obtain an eight-term CI expansion of $\Phi_{1}{ }^{[2,1]}$ based upon the configurations of NO's, for the three-electron atoms,

$$
\begin{aligned}
\Phi_{1}^{[2,1]}= & C_{11}\left(\begin{array}{c}
u_{1} u_{2} \\
u_{2}
\end{array}\right)+C_{21}\left(\begin{array}{l}
u_{1} u_{3} \\
u_{3}
\end{array}\right)+C_{31}\left(\begin{array}{l}
u_{1} u_{3} \\
u_{3}
\end{array}\right) \\
& +C_{41}\left(\begin{array}{l}
u_{2} u_{3} \\
u_{3}
\end{array}\right)+C_{51}\left(\begin{array}{l}
u_{2} u_{2} \\
u_{3}
\end{array}\right)+C_{61}\left(\begin{array}{l}
u_{1} u_{1} \\
u_{2}
\end{array}\right) \\
& +C_{71}\left(\begin{array}{l}
u_{1} u_{3} \\
u_{2}
\end{array}\right)+C_{72}\left(\begin{array}{l}
u_{1} u_{2} \\
u_{3}
\end{array}\right) .
\end{aligned}
$$

Table IX gives the values of the coefficients $C_{k i}$ for each of the atoms discussed in this article assuming that each tableau function is normalized. As can be seen the values for $C_{k i}$ fall off rapidly from the value for the principal configuration. The values of $P_{k}$ are also given in Table IX. These are just $C_{k i}{ }^{2}$ for all configurations 
except 7 in which case

$$
P_{7}=C_{71}^{2}+C_{71} C_{72}+C_{72}^{2} \text {. }
$$

For the ${ }^{3} S$ state of Be there are four NO's and these give rise to 13 configurations and 15 functions. The expansion is

$$
\Phi_{1}^{\left[2,1^{2}\right]}=C_{11}\left(\begin{array}{l}
u_{1} u_{1} \\
u_{2} \\
u_{3}
\end{array}\right)+C_{21}\left(\begin{array}{l}
u_{1} u_{1} \\
u_{2} \\
u_{4}
\end{array}\right)+C_{31}\left(\begin{array}{l}
u_{1} u_{1} \\
u_{3} \\
u_{4}
\end{array}\right)
$$$$
+C_{41}\left(\begin{array}{l}
u_{1} u_{2} \\
u_{2} \\
u_{3}
\end{array}\right)+C_{51}\left(\begin{array}{l}
u_{1} u_{2} \\
u_{2} \\
u_{4}
\end{array}\right)+C_{61}\left(\begin{array}{l}
u_{2} u_{2} \\
u_{3} \\
u_{4}
\end{array}\right)
$$$$
+C_{71}\left(\begin{array}{l}
u_{1} u_{3} \\
u_{2} \\
u_{3}
\end{array}\right)+C_{81}\left(\begin{array}{l}
u_{1} u_{3} \\
u_{3} \\
u_{4}
\end{array}\right)+C_{91}\left(\begin{array}{l}
u_{2} u_{3} \\
u_{3} \\
u_{4}
\end{array}\right)
$$$$
+C_{10,1}\left(\begin{array}{l}
u_{1} u_{4} \\
u_{2} \\
u_{4}
\end{array}\right)+C_{11,1}\left(\begin{array}{l}
u_{1} u_{4} \\
u_{3} \\
u_{4}
\end{array}\right)+C_{12,1}\left(\begin{array}{l}
u_{2} u_{4} \\
u_{3} \\
u_{4}
\end{array}\right)
$$$$
+C_{13,1}\left(\begin{array}{l}
u_{1} u_{2} \\
u_{3} \\
u_{4}
\end{array}\right)+C_{13,2}\left(\begin{array}{l}
u_{1} u_{3} \\
u_{2} \\
u_{4}
\end{array}\right)+C_{13,3}\left(\begin{array}{l}
u_{1} u_{4} \\
u_{2} \\
u_{3}
\end{array}\right) \text {, }
$$

$$
P_{13}=C_{13,1^{2}}+C_{13,2^{2}}+C_{13,3^{2}}
$$

$$
+\frac{2}{3}\left(C_{13,1} C_{13,2}-C_{13,1} C_{13,3}+C_{13,2} C_{13,3}\right) \text {. }
$$

Table $\mathrm{X}$ gives the $C_{k i}$ and $P_{k}$ for this function.

Examination of Tables IX and X shows that for the
${ }^{2} S$ systems the singly excited configuration has a small value of $P_{i}$, whereas for the ${ }^{3} S$ system configuration 13 which is a singly excited one has the second largest $P_{i}$. Because of Brillouin's theorem this suggests that the NO's are rather closer to the SCF orbitals for the doublet systems than for the triplet system.

\section{COMPARISONS WITH OTHER CALCULATIONS}

The calculations discussed in this article were done on the IBM 360/65J computer in the University of Nebraska Computational Center. For one set of exponential scale factors in the STO's the three-electron problem takes approximately $90 \mathrm{sec}$ and the fourelectron problem $360 \mathrm{sec}$ using the method described in Ref. 5. Since there are no orthogonality constraints in this method, there are no Lagrange multipliers and hence no orbital energies. The times required to calculate the NO's and NSO's were not significant.

Since the present calculations include radial correlation only, the energies should be compared to those from an $S$-only CI calculation. Brown and Fontana ${ }^{11}$ have given such a calculation for ${ }^{2} S \mathrm{Li}$ with the resulting energy of -7.44722 a.u. for 79 configurations. Comparison with the energy of the present calculation of -7.44746 a.u. shows this one to be slightly better. There appears to be no comparable $S$-only CI for the ${ }^{3} S$ Be state for comparison with these results.

* Based in part upon the thesis presented by R. D. Koller to the Graduate College of the University of Nebraska in partial fullfilment of the requirements for the $\mathrm{Ph} . \mathrm{D}$. degree.

t NASA Trainee 1968-1970. NSF Trainee 1970-1971.

E. P. Wigner, Group Theory (Academic, New York, 1959).

${ }^{2}$ G. A. Gallup, J. Chem. Phys. 48, 1752 (1968).

${ }^{3}$ D. E. Rutherford, Substitutional Analysis (Edinburgh University Press, London, 1948).

${ }_{4}^{4}$ P.-O. Lowdin, Phys. Rev. 97, 1509 (1955).

${ }^{5}$ L. G. Heikes and G. A. Gallup, J. Chem. Phys. 52, 888 (1970).

${ }^{6}$ C. S. Lin, Theor. Chim. Acta. 15, 73 (1969).

${ }^{7}$ C. Edmiston and M. Krauss, J. Chem. Phys. 49, 192 (1968).

${ }^{8}$ G. A. Gallup, J. Chem. Phys. 50, 1206 (1969).

${ }^{9}$ G. A. Gallup, J. Chem. Phys. 52, 893 (1970).

${ }^{10}$ P.-O. Löwdin, Adv. Chem. Phys. 2, 207 (1959).

11 R. T. Brown and P. R. Fontana, J. Chem. Phys. 45, 4248 (1966). 